\title{
Effect of Nitrogen Nutritional Stress on Some Growth Parameters of Zea mays L. and Vigna unguiculata (L.) Walp.
}

\author{
Akinbode Foluso OLOGUNDUDU ${ }^{1 *}$, Adekunle ADELUSI² \\ ${ }^{1}$ Wesley University of Science and Technology, College of Natural and Applied Sciences, Department of Biological \\ Sciences, P.M.B. 507, Ondo, Ondo State, Nigeria; akinbodefoluso@yahoo.com ( ${ }^{*}$ corresponding author) \\ ${ }^{2}$ Obafemi Awolowo University, Department of Botany, Ile-Ife, Nigeria
}

\begin{abstract}
This study investigated the responses of maize (Zea mays L.) and cowpea (Vigna unguiculata L. Walp.) seedlings growth parameters to nitrogen nutritional stress. This was with a view to determining whether nitrogen nutritional stress would retard or enhance maize and cowpea growth, partly, wholly or not at all through its effect on biomass accumulation and some morphological parameters. Germination of seeds was done using treated sand in sixty plastic pots. A group of the seedlings was nutrient stressed by administering $200 \mathrm{ml}$ of complete nutrient solution minus nitrogen (-N) while the other groups were fed with five times (X5N) and ten times (X10N) the optimal concentration of nitrogen and the last regime was fed with full nutrient solution (FN). The effects of optimal concentration and nitrogen stress on the growth rates (as measured by their fresh and dry weight) were studied. The result of the growth analysis showed that there was increase in shoot height with supraoptimal concentrations of nitrogen treatments $(\mathrm{X} 10 \mathrm{~N}$ and $\mathrm{X} 5 \mathrm{~N})$ while there was a decrease in shoot height with minus nitrogen $(-\mathrm{N})$ regimes. The observed higher biomass (dry matter yield) under the FN regimes in both Zea mays and Vigna unguiculata were attributed to optimal nutrient assimilation rate.
\end{abstract}

Keywords: biomass, metabolism, morphological parameters, optimal, stress

\section{Introduction}

A biological stress is defined as any change in environmental conditions that might reduce or adversely change a plant growth or development (Levitt, 1980). Any change in the environment that results in plant response that is less than the optimum might be considered stressful (Salisbury and Ross, 1991). In plants, water and nutritional deficiency, high salinity and extreme temperature are some of the most studied stress factors (Lambers and Jones, 1998). In both natural and agricultural conditions, plants are frequently exposed to unfavorable environments that results in some degrees of stress (Hasegawa et al., 2000). Water deficit, heat stress, chilling and freezing, salinity, oxygen and nutrient are major stress factors restricting plant growth such that biomass or agronomic yield at the end of the season express only a fraction of the plant's genetic potential (Bray and Bailey-Serres, 2000). In addition, stress plays a major role in determining how soil and climate limit the distribution of plant species (Shinozaki, 2000). Thus understanding the physiological process that underlies stress injury and the adaptation and acclimation mechanisms of plants to environmental stress is of immense importance to both agriculture and the environment (Hong and Vierling, 2000). Nutrient stress can result either from the form in which the nutrient exist, the process by which they become available to the plant; content of soil solution and soil $\mathrm{pH}$ (Evans, 1989). The demand by a plant for a given nutrient changes with time because it is influenced by changes in all other environmental factors that control plant growth which include other nutrients, water, radiation, temperature and age among others (Hartung et al., 1998). Nutrient stress can be evaluated as the proportion by which the growth rate of the plant or crop is limited by that nutrient under the prevailing conditions. It affects all aspects of growth and so should be quantified in terms of growth parameters such as dry weight and biomass accumulation (Pollock and Cairns, 1991). The present study is expected to provide more definite information on the effect of nitrogen nutritional stress on some aspects of the primary metabolic activities of plants.

Nitrogen is one of the important nutrients required for normal plant growth and a close relationship has been found between plant growth and nitrogen supply (Chandra and Mishra, 1991; Vanghan, 1990). However continuous cultivation of crops in addition to adverse environmental factors make the arable soils deficient of nitrogen along with the other important nutrient and the crops grown on such soils exhibit very destructive deficiency symptoms such as poor growth, chlorosis, necrosis of leaves and disorders in many physiological and biochemical characteristics (Bray and Bailey-Serres, 2000). Because of considerable uptake and utilization of nitrogen nutrient, its deficiency frequently occurs in most soils (Ashraf 
80

and McNelly, 1994; Marschner, 1995). In existing literature, nitrogen deficiency is known to effectively presume metabolic process in plants. For instance, it was presumed that nitrogen deficiency leads to disruption of the fine structures of chlorophyll and instability of the pigment protein complex (Reddy and Dakora, 2007) An increase in the nitrogen supply not only delays senescence and stimulates growth, but also change plant morphology in a typical manner, particularly if the nitrogen availability is high in the rooting medium during early growth stages (Graham and Vance, 2000). In several species, it has been observed that local $\mathrm{NO}_{3}$ application induces root proliferation due to an increased growth of laterals (Zhang and Forde, 2000). Yoshida and Tadano (1989), found typical nitrogen induced changes in leaf morphology in rice. The length, width, and area of the leaf blades increase, but the thickness decrease. In addition, the leaves become increasingly droopy, an effect that interferes with light interception (Lindo et al., 1982). In cereals, the enhancement of stem elongation by nitrogen increases the susceptibility to lodging. This change in shoot morphology is less distinct with ammonium than with nitrate-nutrition (Sommer and Six, 1982), and is presumably related to nitrogen-induced changes in the phytochrome balance. The response of leaf photosynthesis to irradiance is largely dependent on the leaf nitrogen content (Sachs, 1996). Photosynthetic enzymes including large amounts of Ribulose biphosphate carboxylase oxygenase (Rubisco) and, to a lesser extent, light harvesting complex proteins, represents a large proportion of total leaf nitrogen (Evans, 1989; Field and Mooney 1986). Nitrogen supply increases the leaf area of plants and canopies to a greater extent than on leaf and canopy photosynthesis (MacDonald, 1986). The increase in leaf area of plants and canopies is brought about by a large effect of nitrogen supply on the expansion of individual leaves and on branching, or tillering in grasses (Gastal, 2002; Vos and Biemond, 1992). However, a number of other species do show a significant effect of nitrogen on the rate of leaf appearance (Cruz and Boval, 2000). In all instances, the impact of nitrogen on leaf expansion rate of grasses was related more to the effect of nitrogen on cell production than cell elongation rate (Drew and Morgan, 2000). In dicots, early studies conducted showed that the impact of nitrogen supply on leaf growth was mostly due to an increased cell growth rate, because a large final cell size was observed and nitrogen supply seemed to increase leaf water potential (Radin and Ackerson, 2001).

Nutritional deficit especially nitrogen triggers a number of response that are expressed by changes in the shoot: root ratio and in the metabolism of leaves and reserve organs (Roberts et al., 1992). The reduction of cell division and cell expansion, leaf production and photosynthesis are evident effects of nitrogen deficiency (Chapin et al., 1988).

\section{Materials and methods}

\section{Soil treatment and germination of seedlings}

Seedlings of Zea mays L. ('SWAN1') and Vigna unguiculata L. ('Ife Brown' variety) were utilized in the experiment. Soil was treated by soaking sand in $1 \mathrm{~N}$ hydrochloric acid for one hour to eliminate microbes and solubilize mineral elements which might be present in it. The acid was drained off and the sand washed with tap water and then distilled water until the $\mathrm{pH}$ of the decantable water was between 6 and 7, which was optimal for the germination and growth of the seedlings. The washed sand was air dried and transferred into sixty plastic pots (about 24 $\mathrm{cm}$ in diameter and $21 \mathrm{~cm}$ in depth) each with four holes of approximately $4 \mathrm{~mm}$ in diameter bored at the bottom to enhance drainage during the course of the experiment. Ten seeds were planted in each pot and after germination thinned to five. The plants were exposed to approximately eight hours of sunlight daily. Each bowl was supplied with $200 \mathrm{ml}$ of distilled water in the morning and evening during the first 6 days after planting. After germination and on the $7^{\text {th }}$ day after planting, the pots were divided into four nutrient regimes each containing fifteen pots, each pot containing five seedlings. The experiment was repeated and carried out under the same condition.

\section{Nutrient solution composition and application of nutrient regimes}

This was prepared according to the modified Long Ashton Formular (Hewitt, 1952). The nutrient solution composition were given the subscripts; FN, X5N, X10N, and $-\mathrm{N}$

\section{Weight Analysis}

Weight analyses were carried out on ten seedlings harvested at random (sampling procedure) from each nutrient regime. The plants were carefully uprooted, blotted dry, weighed fresh and then placed inside a labeled envelope and kept in a Gallenkamp drying oven set at $80^{\circ} \mathrm{C}$ to dry constant weight.

\section{Measurement of physical parameters}

A meter rule was used to measure the following parameters: leaf length, leaf width and shoot height from soil level to the terminal end and the number of leaves per plant were noted. The fresh weight was taken after which the plants was dried at $80^{\circ} \mathrm{C}$ in a Gallenkamp oven until a constant weight was achieved. After cooling, the dry weight was determined. The dried samples were separated into leaves, shoots and roots and their different dry weights determined. These were kept for further analysis.

\section{Growth Analysis}

The following plant growth parameters were determined from the data obtained from the physical parameters (Osei-Yeboah and Jiang, 1988) 
Leaf Area (LA)

$\mathrm{LA}=\mathrm{L} \times \mathrm{W} \times 2.325$

The unit of LA is $\mathrm{cm}^{2}, \mathrm{~L}$ and $\mathrm{W}$ are leaf length and width respectively while 2.325 is the correction factor.

\section{Leaf Area Ratio (LAR)}

$\mathrm{LAR}=\mathrm{LA} / \mathrm{WS}$

LAR accounts for the total surface area used for assimilation power unit of plant biomass present. The unit is $\mathrm{cm}^{2} \mathrm{~g}^{-1}, \mathrm{~W}_{\mathrm{S}}$ is plant dry weight.

\section{Leaf Weight Ratio (LWR)}

$\mathrm{LWR}=\mathrm{W}_{1} / \mathrm{W}_{S}$

LWR defines assimilation in terms of leaf density: the unit is $\mathrm{g}^{-1}, \mathrm{~W}_{1}$ is the leaf dry weight.

\section{Root Shoot Ratio (RSR)}

$\mathrm{RSR}=\mathrm{W}_{3} / \mathrm{W}_{2}$

Root shoot ratio defines the method of assimilate partitioning, $\mathrm{W}_{2}$ and $\mathrm{W}_{3}$ are shoot and root dry weight respectively, the unit is $\mathrm{g}^{-1}$

\section{Statistical analysis}

A two way analysis of variance (ANOVA) was performed using Statistical Analysis System (SAS) software version 9.1 (SAS, 2003). The data were first tested between normality and assumption of constant variance. Post hoc testing was carried out using Duncan Multiple Range Test (DMRT) to separate the significance means at 0.05 , confidence limit (alpha level) for the mean.

\section{Results}

The heights of the shoots of the cowpea and maize plants recorded similar pattern of growth for a greater part of the experimental period (Fig. 1a and 1b). There was no significant difference $(p>0.05)$ in the control (FN). However, X10N was significantly different.

In line with the pattern of growth in cowpea regimes (Fig. 2a), the leaf biomass of the maize plants increased gradually for a greater part of the experimental period (Fig.

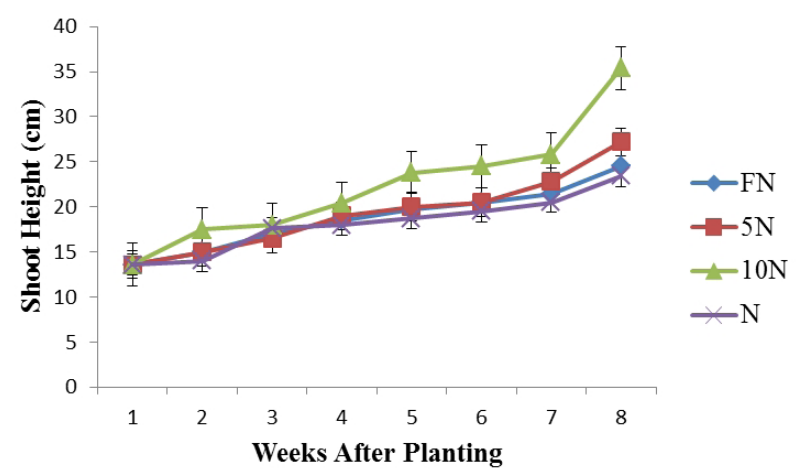

Fig. 1a. The effect of nitrogen nutritional stress on the shoot height of Vigna unguiculata measured at different periods 2b). Meanwhile, there were lags in peak periods of leaf biomass on the $45^{\text {th }}$ day in $\mathrm{FN}$ and on the $52^{\text {nd }}$ day in $\mathrm{X} 10 \mathrm{~N}$ and $-\mathrm{N}$ regimes respectively. Also, there was no significant difference $(p>0.05)$ in the control (FN). However, X10N was significantly different.

The shoot biomasses in maize and cowpea plants follow a similar linear pattern and were approximately equal throughout the experimental period (Fig. $3 \mathrm{a}$ and $3 \mathrm{~b}$ ). Again, results of the ANOVA showed that there was no significant difference $(p>0.05)$ in the control (FN). However, $\mathrm{X} 5 \mathrm{~N}$ and $\mathrm{X} 10 \mathrm{~N}$ were significantly different.

The root biomass of FN and X5N increased rapidly during the course of the experiment with both reaching their peak on the $45^{\text {th }}$ day (Fig. 4a). These particular patterns were also recorded in the maize regimes during this period (Fig. 4b).There was no significant difference $(p>0.05)$ in the control (FN), X10N and $-\mathrm{N}$ treatments. However, $\mathrm{X} 5 \mathrm{~N}$ was significantly different.

The number of leaflets/plant in all treatments followed a regular linear pattern for a greater part of the experimental period (Fig. 5a). In the maize seedlings grown under the different treatments, such patterns of growth were also recorded during the period of the experiment (Fig. 5b). There was no significant difference $(p>0.05)$ in the control (FN), $\mathrm{X} 10 \mathrm{~N}$ and $-\mathrm{N}$ treatments. However, $\mathrm{X} 5 \mathrm{~N}$ was significantly different.

The leaf area ratio (LAR) of $\mathrm{X} 5 \mathrm{~N}$ and $\mathrm{X} 10 \mathrm{~N}$ respectively alternated between rapid increase and decrease for a greater part of the experimental period (Fig. 6a). However, in FN and X5N, LAR maintained a similar plateau throughout the experimental period. In the same vein with cowpea plants, the maize LAR in X10N and $-\mathrm{N}$ treatments increased till the $45^{\text {th }}$ day after which they decreased for the remaining part of the experimental period (Fig. 6b).

There was no significant difference $(p>0.05)$ in the control (FN), X10N and X5N treatments. However, $-\mathrm{N}$ was significantly different.

The leaf weight ratio (LWR) of all regimes decreased for a greater part of the experimental period (Fig. 7a). In contrast to LWR in cowpea, maize LWR was inconsistent

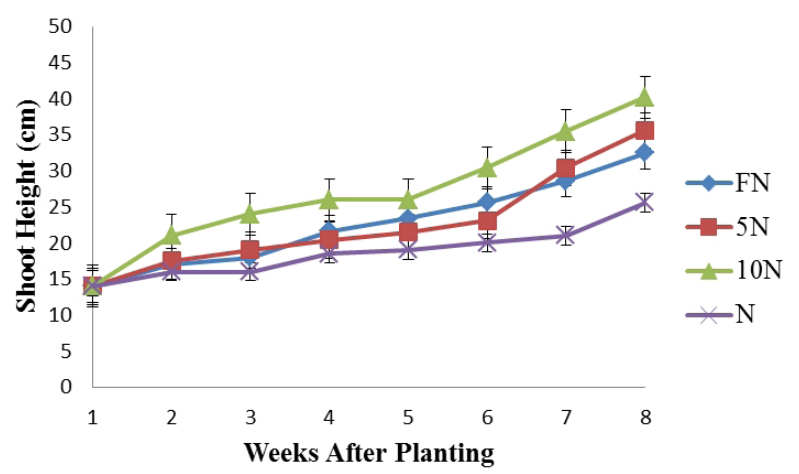

Fig. 1b. The effect of nitrogen nutritional stress on the shoot height of Zea mays measured at different periods 
82

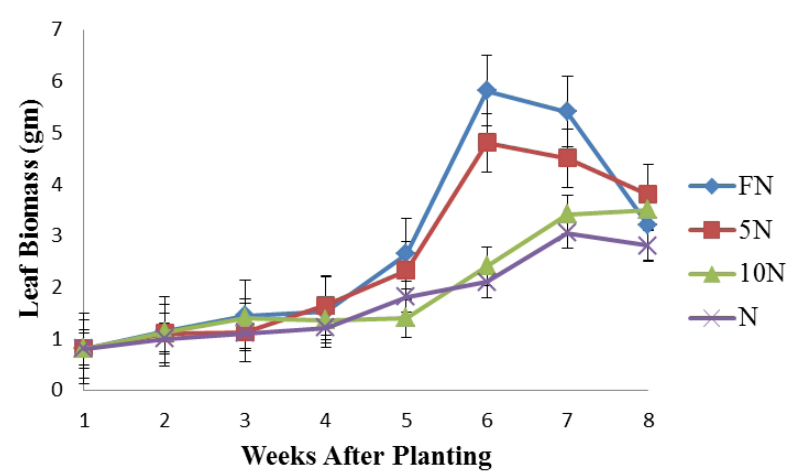

Fig. 2a. The effect of nitrogen nutritional stress on the leaf biomass of Vigna unguiculata measured at different periods

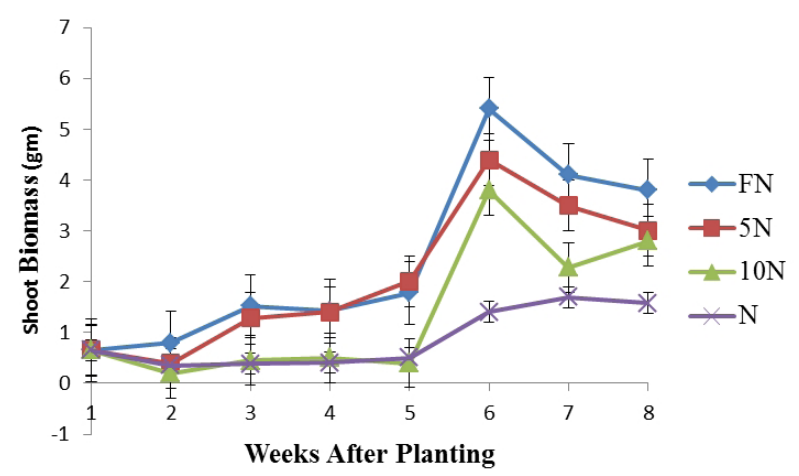

Fig. 3a. The effect of nitrogen nutritional stress on the shoot biomass of Vigna unguiculata measured at different periods

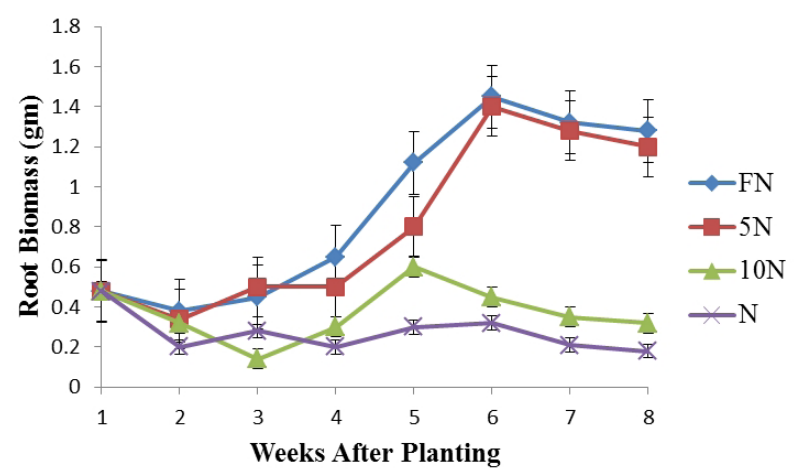

Fig. 4a. The effect of nitrogen nutritional stress on the root biomass of Vigna unguiculata measured at different periods

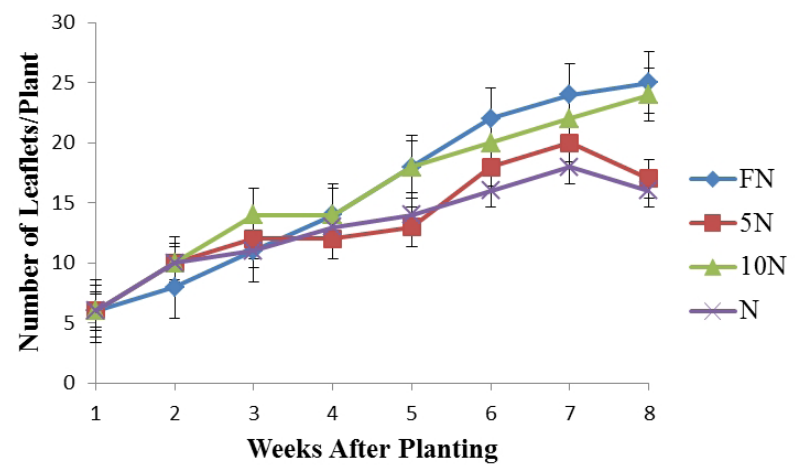

Fig. 5a. The effect of nitrogen nutritional stress on the number of leaflets/plant of Vigna unguiculata measured at different periods

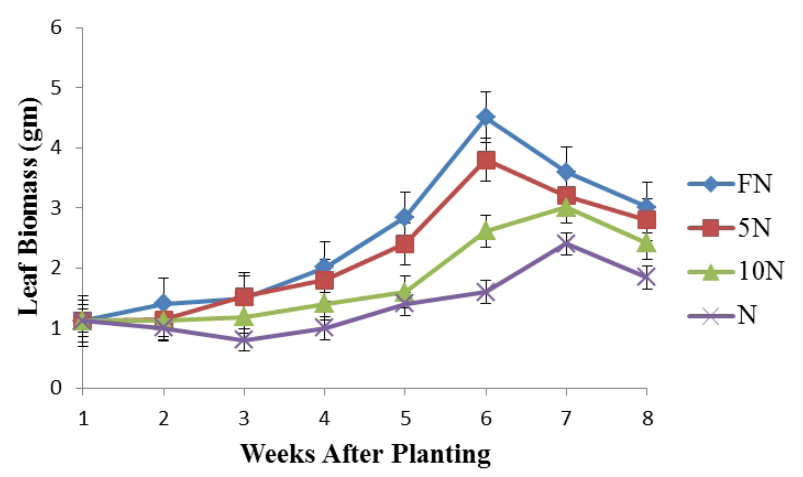

Fig. 2b. The effect of nitrogen nutritional stress on the leaf biomass of Zea mays measured at different periods

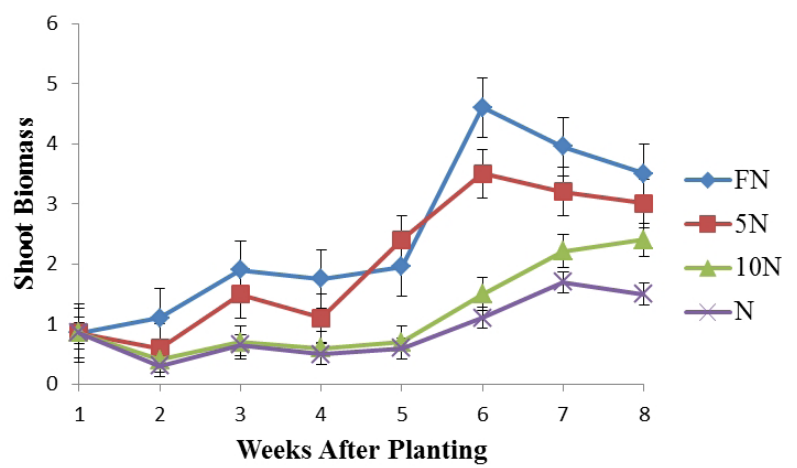

Fig. 3b. The effect of nitrogen nutritional stress on the shoot biomass of Zea mays measured at different periods

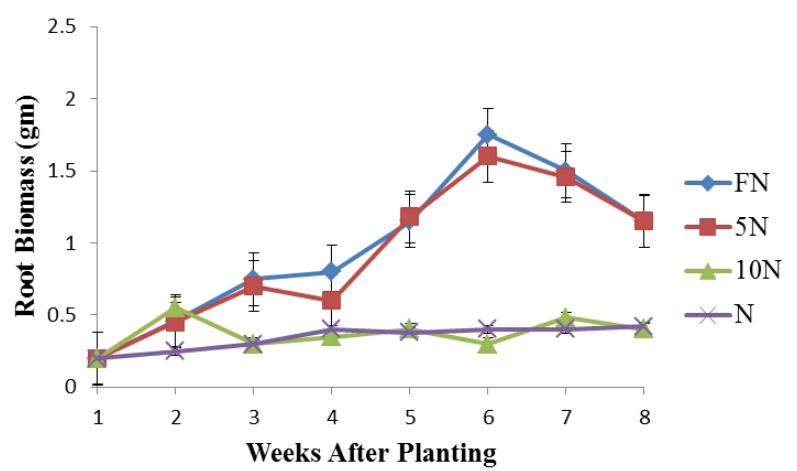

Fig. $4 \mathrm{~b}$. The effect of nitrogen nutritional stress on the root biomass of Zea mays measured at different periods

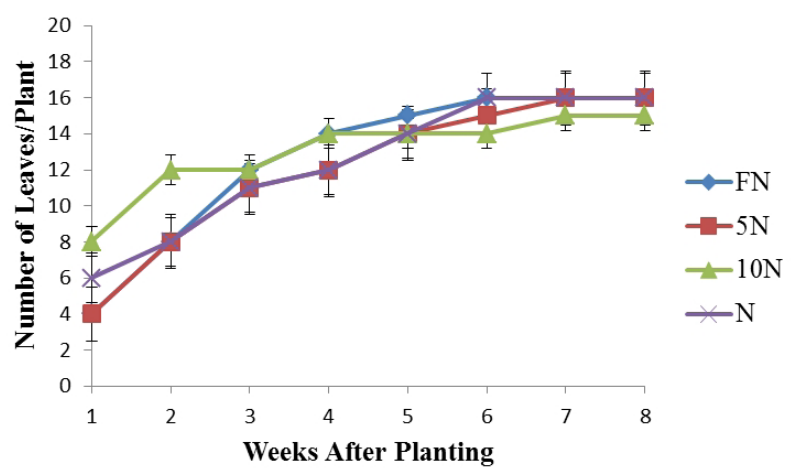

Fig. 5b. The effect of nitrogen nutritional stress on the number of leaves of Zea mays measured at different periods 


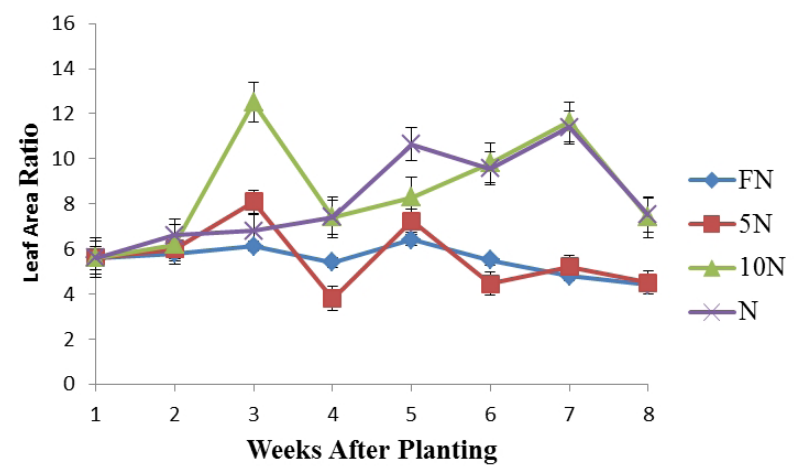

Fig. 6a. The effect of nitrogen nutritional stress on the leaf area ratio of Vigna unguiculata measured at different periods

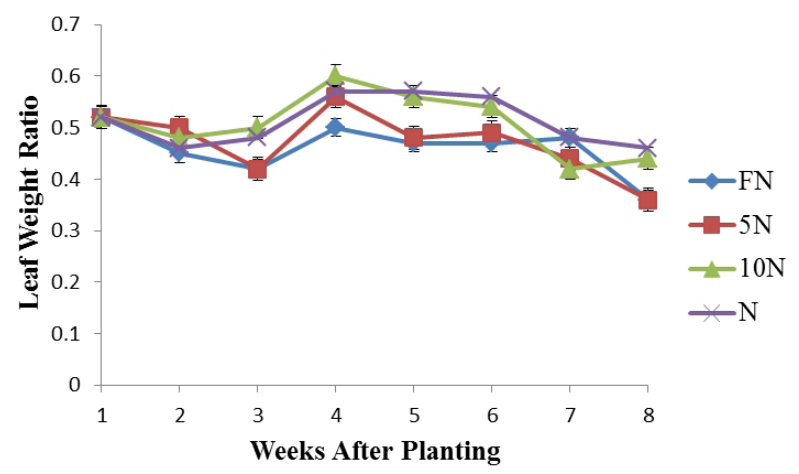

Fig. 7a. The effect of nitrogen nutritional stress on the leaf weight ratio of Vigna unguiculata measured at different periods

in growth patterns as the LWR of all the regimes alternated between increase and decrease throughout the experimental period (Fig. 7b).

\section{Discussion}

In the cowpea regimes, the $\mathrm{X} 10 \mathrm{~N}$ regime had the highest shoot height. The plants can be said to have devoted more of their nutrient for stem extension as apical dominance were more pronounced in them than in X5N regime (Thomas and Raper, 1983). This was in agreement with the results of Bouma and Nielsen (2000) and Bonifas et al. (2005) that plants growing in supraoptimal concentration of nutrient respond to nutrient stress by devoting more of their available carbon to shoot growth resulting in elongated stems. The FN plants had adequate nutrient supply and so do not require extra carbon for root growth; this invariably led to the normal plant height and short peduncles observed in this regime. The observed higher biomass (dry matter yield) under the FN regime can be attributed to optimal rate of photosynthesis, adequate nutrient and greater leaf surface area. Adequate nutrient supply increased the dry matter production in an optimal condition; a situation that corroborated the findings of Peace and Grubb (1982) and Thompson et al. (2000) that higher dry weight was attributed to optimal leaf expansion rates. The lowering of the shoot biomass under low

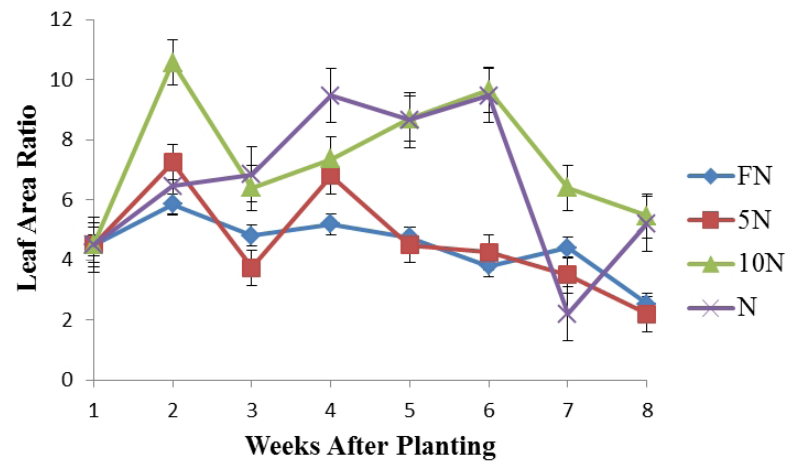

Fig. 6b. The effect of nitrogen nutritional stress on the leaf area ratio of Zea mays measured at different periods

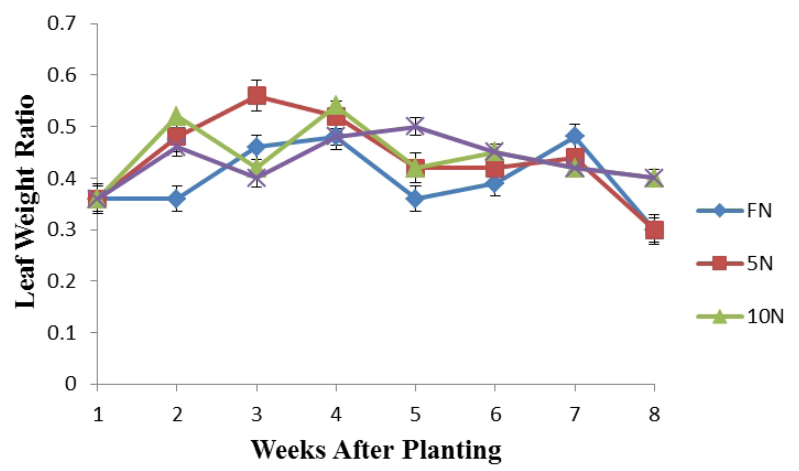

Fig. $7 \mathrm{~b}$. The effect of nitrogen nutritional stress on the leaf weight ratio of Zea mays measured at different periods

nutrient supply may not be unconnected with the reduction in the production of photosynthates as more carbon was diverted to root growth from both stem and leaf tissues (Morgan and Smith, 1981). The production of more leaves under the optimal nutrient concentration (FN) may be a mechanism evolved by cowpea plants to increase total surface area for photosynthesis due to reduced leaf area (Morgan and Smith, 1981). In the $-\mathrm{N}$ regime, there was increase in leaf abscission and reduction in the number of leaves produced due to the fact that the extra carbon needed for greater root growth as a result of low nutrient supply was taken from their non-assimilatory tissue as well as leaf tissue (Peace and Grubb, 1982) and so stem component production was proportionately less in nutrient stressed plants. The trend in the leaf area ratio showed that the $\mathrm{X} 10 \mathrm{~N}$ regime had a higher leaf area ratio than the $\mathrm{X} 5 \mathrm{~N}$ regime as a consequence of nutrient addition; more leaves which led to a higher surface area for photosynthesis and so a proportionate high dry matter in plant tissues. There was more or less a direct correlation between the leaf weight ratio and nutrient application. Also, Singh (1978) found that leaf weight ratio increased with increasing nutrient application indicating that photosynthesis is partitioned more to the leaves.

Nitrogen limitation resulted in a reduction in shoot growth and photosynthetic capacity in maize (Foyer and Lethoeneau, 1990). However, this was at variance with 
84

the observation of Tischer and Giffen (2000), that an increase in nitrogen supply not only delays senescence and stimulates growth but also changes plant morphology in a typical manner, particularly if the nitrogen availability is high in the rooting medium during the early growth, shoot elongation is enhanced and root elongation inhibited, a shift which is unfavorable for nutrient acquisition and water uptake in later stages. Nitrogen acquisition is highly related to crop growth rate and to biomass accumulation (Gastal and Bemaire, 2002). Depending on the plant species, developmental stage and organ, the nitrogen content required for optimal growth varies between 2 and $5 \%$ of the plant dry weight. The biomass accumulation (dry weight) of an organ may reflect, among other things the rate of movement of solute into the organ (Renalto $e t$ al., 1997). The biomass accumulation in the FN regime could therefore indicate optimal acquisition and uptake of nitrogen for efficient metabolic activities. Renalto (1997) emphasized the importance of nitrogen in the distribution of proteins in the leaves.

\section{Conclusions}

This study has to a larger extent emphasized the importance of biomass in dictating the growth pattern of other morphological parameters. It also contributed to the relationship between nitrogen nutritional stress, metabolic activities and photosynthetic apparatus in the species under study.

\section{References}

Ashraf SD, Nelly MC (1994). The effects of growing beans together with maize on incidence of bean diseases and pests. Neth J Plant Pathol 78:12-18.

Bonifas KD, Lindquist JL (2000). Predicting biomass partition to root versus shoot in corn and velvet leaf. Weed Sci 53:670-675.

Bonifas KD, Walters DT, Lindquist JL (2005). Nitrogen supply affects root: shoot ratio in corn and velvet leaf. Weed Sci 54:133-137.

Bouma TJ, Nielsen KL (2000). Sample preparation and scanning protocol for computerized analysis of root length and diameter. Plant and Soil 218:185-196.

Bray EA, Bailey-Serres J (2000). Responses to abiotic stress, 1158-1203 p. In: Biochemistry and Molecular Biology of Plant. American Society of Plant Physiologists, Rockville, MD.

Bridges DC (1992). Crop losses due to weeds in the United States-1992. Weed Science Soc of America, Champaign, IL.

Caldwell MM, Richards JH (1996). Competing root systems: Morphology and models of absorption: On the Economy of Plant Form and Function,New York, Cambridge University Press, 251-273 p.

Chandra RA, Mishra NE (1991). Test of an ascorbic acid meth- od for determining phosphorus in water and $\mathrm{NaHCO} 3 \mathrm{ex}-$ tracts from soil. Soil Sci Soc Am Proc 29:677-678.

Cracker TA (1983). Nutrient uptake by intercropped maize and cowpeas and a concept of Nutrient Supplementation Index (NSI). Exp Agric 97:263-275.

Cruz ER, Boval NJ (2000). Shading and temperature as environmental factors affecting growth nodulation and symbiotic nitrogen fixation in soybean. Agron J 72:305-308.

Drew MC, Morgan PW (2000). Programmed cell death and aerenchyma formation in roots. Trends in Plant Science 5:123-127.

Evans JR (1989). Photosynthesis and nitrogen relationship in leaves of $\mathrm{C}_{3}$ plants.

Field ZF, Mooney JE (1986). Aspects of the comparative physiology of grain yield in cereals. Adv Agron 28:301-359.

Foyer TA, Lethoeneau DK (1990). Two examples of natural enemy augmentation: Researching the Ecological Basis for Sustainable Agriculture. Springer-Vierlag, New York, 1-29 p.

Gastal TR (2002). Effect of alfalfa leaf extracts and phenolic allelochemicals on early seedling growth and root morphology of alfalfa and barynarg grass. Crop Prot 5:1077-1082.

Gastal KL, Bemaire GC (2002). Row spacing effect of nitrogen fixation, nitrogen yield and soil nitrogen uptake of intercropped cowpea and maize. J Plant and Soil 111:17-23.

Graham SJ, Vance YR (2000). The Glycine-Glomus-Rhizobium symbiosis IV. Interactions between mycorrhizal and nitrogen-fixing Endophytes. Plant Cell Envir 10:607-617.

Hartung W, Wilkinson S, Davies WJ (1998). Factors that regulate absiscic acid concentrations at the primary site of action at the guard cell. J Mol Microbiol Biotechnol 1:231-242.

Hasegawa PM, Bressan RA, Zhu JK, Bohnert HJ (2000). Plant cellular and molecular responses to high salinity. Annu Rev Plant Physiol Plant Mol Biol 51:463-499.

Hewitt EJ(1952). Sand and water culture methods used in the study of plant nutrition. Commonw Bur Horts Plantatio Crops Grt Brt Tech Comm No.22.

Hilbert DW(1990). Optimization of plant root:shoot ratios and internal nitrogen concentration. Ann of Bot 66:91-99.

Hong SW, Vierling E (2000). Mutants of Arabidopsis thaliana defective in the acquisition of tolerance to high temperature stress. Proc Natl Acad Sci USA 97:4392-4397.

Junk RT, Ahmed S, Rao MR (1982). Performance of maizesoybean intercrop combinations in the tropics: Results of a multi- location study. Field Crop Res 5:147-161.

Lambers J, Jones TL (1998). Plant physiological ecology. Springer-Verlag, New York.

Levitt J (1980). Responses of Plants to Environmental Stresses. Academic Press, New York.

Lindo MA, Arny ST, Upper FR (1982). Nitrogen dynamics and management in rice-legume cropping system. Advan Agron $45: 1-59$ 
Lindquist ST (1996). Legume-maize association influences crop characteristics and yields. $4^{\text {th }}$ international crop science congress. Oct. 1996, Brisbane, Australia.

Mac Donald LA (1986). Seasonal pattern of growth and nitrogen fixation in field-grown pea. Plant and Soil 101:45-76.

Marschner H (1995). Mineral nutrition of higher plants. Academic Press, London, 889 p.

Morgan DC, Smith H (1981). Control of development in Chenopodium alnum. L. by shade light. The effect of light quantity and light quality. New Phytol 88:239-248.

Osei-Yeboah G, Jiang P (1988). Growth and variations in proline, sodium, chloride, phosphorus and potassium concentrations of chicken pea varieties under salinity stress. Turkish J 24:649-654.

Pandy BN, Sinha RP (2000). Light as a factor of growth and morphogenesis. New Phytol 38(2):395-400.

Peace WJH, Grubb PJ (1982). Interaction of light and mineral nutrient supply in the growth of Impatiens parviflora. New Phytol 90(1):127-150.

Pollock FT, Cairns MD (1991). Nitrogen transfer and dry matter production in soybean and sorghum mixed cropping systems at different population densities. Soil Sci Plant Nutri 36:233-241.

Radin LW, Ackerson KA (2001). Nitrogen fixation and transfer in an intercropping systems. Field Crops Res 34:344-400.

Reddy MA, Dakora FD (2007).Yield components of nodulated cowpea (Vigna unguiculata) and maize (Zea mays) plants grown with exogenous phosphorus in different cropping systems. Australian J Exp Agric 47:583-589.

Renalto CK, Bernett MA, Creamer NG (1997). Evaluation of cover crop mixtures for use in vegetable production systems. Hort Sci 32:866-870.

Roberts LA, Hooks JD, Edwards SM (1992). Intercrop performance of Pearl millet, amaranthus, cowpea, soybean and guar in response to planting pattern and nitrogen fertilization. Agron J 86:1097-1102.

Sachs MM (1996). Alteration of gene expression during environmental stress in plants. Annu Rev Plant Physiol 47:1-15.

Salisbury FB, Ross CW (1991). Plant Pyhsiology. Wadsworth Inc., Belmont.
85

Schinozaki K (2000). Molecular responses to dehydration and low temperature. Curr Opinion in Plant Biol 217-223 p.

Singh BG (1978). Effect of shade on the growth of spring barley. Qyton 36(1):53-60.

Sommer FV, Six JL (1982). Competitive ability and growth habitat of indeterminate beans and maize for intercropping. Field Crops Res.6:45. sorghum/groundnut intercrop. Agric For Meteorol 53:285-310.

Statistical Analysis System (2003). (SAS) software version 9.1 (SAS, 2003) US Incorp.

Taylor BH (1993). Effect of $\mathrm{N}$ fertilization on yield, growth and extraction of water by wheat following soybean and grain sorghum. Agron J 76:117-135.

Thomas JF, Raper CD (1983). Photoperiod effects on soybean growth during the onset of reproductive development under various temperature. Plants Bot Gazette 144(4):471-476.

Thompson WA, Stocker GC, Kriedemann PE (2000). Growth and photosynthetic response to light and nutrients of Flindersia brayleyana. In: Muell F (Ed.). Ecology of Photosynthesis in Sun, a rainforest tree with broad tolerance to sun and shade.

Tischer ET, Giffen ME (2000). Cowpea cover crop in weed control for cowpea in desert bell pepper production. Hort Sci 35(2):135-138.

Vos SR, Biemond RY (1992). Seasonal growth patterns in field beans (Vigna faba) as affected by population density shading and its relationships with soil water. J Agric Sci 88:293-301.

Wang KD (2008). Net nitrogen Balance for cool-season grain legume crops and contributions to wheat nitrogen uptake: A Review. Aust J Exp Agric 41:347-359.

Yoshida BM, Tadano RT (1989). The $\mathrm{N}_{2}$-fixing capacity of peanut cultivars with differing assimilate partitioning characteristics. Aust J Agric Res 45:1455-1468.

Zhang RA, TG Forde (2000).Translocation of photosynthetic products to soybean modules and their role in nitrogen fixation. Plant Physiol 33:118-124. 